\title{
Comments on Brian Epstein's The Ant Trap
}

Katherine Hawley, June 2016

The Ant Trap is a terrific book, which opens up new opportunities to use philosophical methods in the social realm, by drawing on the tools and techniques of contemporary metaphysics. Epstein uses concepts of dependence, constitution, and grounding, of parts and whole, of membership and kindhood, both to clarify existing accounts of social reality, and to develop an account of his own. The first half of the book develops some core concepts and claims, whilst the second half applies these to the study of social groups of various types. I found the whole book to be very rewarding, and deserving of further study, but in these comments I focus upon the ideas of the first half, 'Foundations, Old and New'.

\section{Dependence in Social Metaphysics}

Central to Epstein's contribution is his rigorous examination of a variety of metaphysical dependence relations, and their roles in structuring the social realm. Epstein distinguishes anchoring from grounding, and I return below to challenge this particular distinction: in the meantime I will use 'dependence' as a general term for this sort of relation. I begin by exploring why dependence notions are such a good fit for social metaphysics.

The invocation of dependence has been both popular and controversial within general metaphysics in recent years (e.g. Wilson (2014), Schaffer (2012)). When we use terms such as 'in virtue of' or 'because' in ways which are not obviously causal, it is likely that we are invoking some kind of metaphysical dependence relation. Dependence is an especially useful notion in situations where we want to acknowledge that reality has multiple, interconnected layers. For example, we might be concerned with the relationship between the mental and the physical, between the biological, the chemical and the physical, between wholes and parts, between the normative and the natural, between the abstract and the concrete, or between truths and truthmakers.

In any of these cases, we can formulate views at either of two extremes, plus a range of more moderate views. One extreme view is simply to identify the various layers in question, arguing that the mental just is the physical, wholes just are their parts, the normative just is the natural. There are many details to be ironed out here, and depending on how that goes, we might or might not think of such extreme views as eliminating the 'higher' level facts or entities. The other extreme view is to regard the various layers in question as entirely 
independent of one another; then the obvious concern is how to understand whatever interlevel correlations there seem to be.

In many such cases, both extremes are unappealing, and so we seek out ways of understanding how relatively fundamental, basic, or prior 'lower' levels can generate, underpin, ground, determine, anchor (etc) the higher levels which depend upon them. The goal is to identify an inter-level relationship which can explain correlations without eliminating the higher level entirely, or merely identifying it with the lower level. Such a relation promises intimacy without identity; thus conceived, it is clear that dependence relations are asymmetric, as the 'higher' level depends upon the 'lower', and not vice versa. Why be sceptical about such talk of dependence? There are various reasons to be suspicious, not least the thought that metaphysicians have simply identified a role (asymmetric intimacy without identity) then posited a relation to fill it. We might also hope that, given our preexisting reliance upon modal notions of necessity, possibility, and counterfactuals, we could try to spell out the relevant dependence relations in purely modal terms, without needing a primitive notion of grounding or dependence. This is one way of understanding the project of capturing inter-level metaphysics with the resources of supervenience. But this project has hardly met with resounding success.

However we develop the details, it is extremely natural to draw upon notions of dependence in social metaphysics, since this enquiry is readily conceived of as an exercise in inter-level metaphysics. As with other issues in inter-level metaphysics, the extremes have little appeal: neither eliminating the social, nor regarding it as entirely independent of the nonsocial is a plausible result of investigation, unless as an absolute last resort should more moderate accounts prove irredeemable.

Thus in the first half of The Ant Trap, when Epstein articulates what he (following Guala (2007)) properly calls the 'Standard Model' within social ontology, he does so in terms of dependence relations. Roughly speaking, the idea is that we collectively generate, produce, underpin or make the social world through our beliefs, intentions, speech acts, dispositions, conventions, or what-have-you. Alongside this is the idea that social entities have some kind of physical underpinnings, constituents, or substratum, e.g. as a club is made up of its members, or a dollar bill from a piece of paper. In various ways, all these ideas concern the way in which entities or facts of one kind depend upon those of another. Thinking again of intimacy without identity, some such approach appears crucial to our respecting - rather than 
eliminating - the subject matter of the social sciences, whilst retaining the hope of understanding the social realm in ways which are constrained by, if not determined by, our understanding of the physical world more generally.

\section{Anchoring and Grounding}

Whilst wholeheartedly endorsing Epstein's strategy of using dependence relations to clarify social ontology, I disagree with the detail of how he implements this strategy. But to explain my disagreement, I need to display Epstein's view, and the problem situation he is responding to. As he shows, there are at least two roles for dependence-like notions within social metaphysics; he regards these as fundamentally distinct, deserving the different labels 'anchoring' and 'grounding'.

Epstein borrows from Searle the core example of what makes a certain piece of paper - call it 'Billy' - a dollar bill. (Epstein is commendably sensitive to the fact that Searle's toy example is purged of the many complexities surrounding real-life money, cash, and economic confidence). What makes it the case that Billy is a dollar? On what does this fact depend? Plausibly, in the toy example at least, it depends on facts about Billy's physical make-up and appearance, together with facts about where and how Billy was manufactured. As a shorthand, let us summarise all of these as the fact that Billy is a bill printed by the Bureau of Printing and Engaging. That is, Billy is a dollar in virtue of the fact that Billy is a bill printed by the Bureau of Printing and Engraving, and Billy's being a bill printed by the Bureau of Printing and Engraving explains why Billy is a dollar.

But why is being printed by the Bureau of Printing and Engraving so crucial for being a dollar? Why aren't the pieces of paper printed by Hasbro (the manufacturers of the board game Monopoly) dollar bills? This fact about the conditions for being a dollar seems to require explanation and underpinning in its own right - it is not just a brute fact. And this is where the philosophers of 'social ontology' step in. Searle, for example, argues that this is because we have collectively accepted that bills printed by the Bureau of Printing and Engraving are dollars (and that bills printed by Hasbro are not). Different theories of social ontology will fill this out somewhat differently, giving different accounts of what collective acceptance is, why it is important, how it is achieved, who 'we' are, and so on. Nevertheless, some sort of structure like this seems to be very common both in theorising about the sources of social facts, and in our loose everyday thinking about these matters. 
To take another example central to The Ant Trap, consider what underpins the existence and nature of the social entity which is the US Supreme Court. One important set of underpinning facts concern the nine people who are the justices comprising the Court, facts about their history, interactions with one another and with other people (such as the President), and so on. Another important set of underpinning facts concern the laws and constitution of the US, which together ensure that if any nine people have the relevant properties, history and interactions, then they are justices comprising the Supreme Court. For Epstein, underpinning facts of the first type (where Billy was printed, how those nine people have interacted) are the grounds for the relevant social fact (that Billy is a dollar, that this group of people is the US Supreme Court). Underpinning facts of the second type (that we have collectively accepted that the Bureau of Printing and Engraving can issue dollars, that US laws and constitution specify a certain structure for the Supreme Court) are not grounds but anchors.

\section{Individualisms}

A key advantage of articulating this complex structure is that it enables Epstein to disentangle two versions of 'individualism' about the social realm, two versions of the thought that individual people, as opposed to collectives, are the source of social facts. That is, we can distinguish individualism about grounding facts from individualism about anchoring facts.

Once the question is helpfully articulated in this way, it is obvious that social facts about dollar bills are not fully grounded by facts about individual people: it is piece of paper which constitutes a dollar in this sense, not a person. That said, part of the grounds for being a dollar is having interacted with appropriate people in the Bureau of Printing and Engraving. So even this simple case is not wholly straightforward. Still, it is very useful to distinguish questions about what constitutes the dollar bill from questions about what makes it the case that being constituted in that way suffices to make a piece of paper a dollar; about what, in Epstein's terms, are the anchors for this fact.

Some social entities are more plausibly grounded in individuals - perhaps the Supreme Court is like this (constituted by the nine justices), or, to use a simpler example from The Ant Trap, a mob of people which is constituted by the members of the mob. In such cases we can go on to ask the separate question of what anchors the fact that those people constitute that social entity: the answer here will clearly be much more complex in the case of the Supreme Court than in the case of the street mob. 
Thinking in this way allows us to frame some interesting questions about those social facts which are both grounded in and anchored by facts about individuals. For example, we can distinguish cases in which the grounding and the anchoring individuals are one and the same - where a group is self-creating in some sense - from cases in which the anchoring individuals are 'outsiders' who endow the grounding individuals with a collective social status. There will also be mixed cases, for example where some but not all of the grounding individuals are amongst the anchoring individuals, or where some subset of the grounding individuals form the anchors.

This in turn helps us to think through the ethical and political issues which arise where one group of people imposes a social status upon a different group, for better or for worse, with or without the consent of those people who are imposed upon. Such imposing might be done by outsiders, and/or by a subgroup of the people upon whom the status is imposed. The work of Katharine Jenkins (2016) on 'ontic injustice' comes to mind here, and we might distinguish injustices which are constituted by the very fact of having a social status imposed upon us, from injustices which are constituted by the negative consequences of certain social statuses, whether these are imposed or chosen, welcomed or resented. This gives us a framework for exploring the legitimacy of internal elites, or of 'tyranny of the majority', questions of minority rights in a majoritarian framework, and so on; I write from Scotland in the aftermath of the 'Brexit' vote of June 2016, when such issues feel very pressing.

More generally, it would be fruitful to consider such concerns in connection with the issues Epstein discusses in the second half of the book, about group agency, intentionality, and the like: how, if at all, are these affected when individuals become members of a group against their individual or collective will?

\section{Facts, grounding, anchoring}

So there is plenty to work with here, and it is undeniably useful to distinguish the varying ways in which individual people, collectives, and physical objects can help contribute to generating the social realm. However, I think that Epstein makes life unnecessarily complicated for himself in his treatment of the metaphysics of grounding and of anchoring.

Let us look more closely at the structure which Epstein proposes. I'm afraid this is going to seem very dry, and after a while the words 'grounding' and 'fact' are going to look like abstract shapes rather than anything with semantic content. But this is inevitable, because in my view Epstein has - understandably - failed to separate some issues which are very easily 
confused unless we are extremely cautious with our use of words. Epstein's discussion is rich and subtle, and it is unsurprising that to find problems we need to look very closely.

Here are Epstein's core terms and concepts.

Grounding. Grounding is a metaphysical relation between facts, rather than objects, properties, or relations. The fact that Billy is a bill printed by the Bureau of Printing and Engraving grounds the fact that Billy is a dollar; i.e. Billy is a dollar in virtue of having being printed by the BPE. Or, at the very least, this is an important part of the story.

Grounding facts. Syntax permits two readings of this phrase, so we risk unintentional ambiguities. Grounding facts might be facts which ground, just as working people are people who work, and stimulating ideas are ideas which stimulate. In that sense, grounding facts include the fact that Billy is a bill printed by the Bureau of Printing and Engraving. But in another sense grounding facts are facts about what grounds what, just as causal facts are facts about what causes what (causal facts might be causally inert in their own right), and biological facts are facts about biological matters (biological facts are not living organisms in their own right). In this second sense, grounding facts include the fact that (the fact that that Billy is a bill printed by the Bureau of Printing and Engraving) grounds (the fact that Billy is a dollar). I think Epstein's figure 6B (p.77) represents the first sense of 'grounding fact', whilst its caption represents the second sense; the surrounding discussion doesn't resolve this.

Grounding Conditions. Sometimes grounding conditions seem to be facts which ground (e.g. in figure 6A, p.76 and surrounding discussion) - for example, the fact that Billy was printed by the Bureau of Printing and Engraving. These are grounding facts in the first sense. Other times grounding conditions seem to be facts about what grounds what, i.e. grounding facts in the second sense. But either way, grounding conditions seem more closely connected to social kinds than to individual social facts. After all, there is nothing unique about Billy: social facts about things being dollars are quite generally grounded by facts about them being printed by the Bureau of Printing and Engraving. As I understand Epstein, it is primarily social kinds such as dollar bill which have grounding conditions, whether these are facts which ground, or facts about grounding. But it sometimes seems that individual social entities have grounding conditions too.

Frame Principles. Frame principles 'express' (77) or 'give' (78) grounding conditions, formulations which do not resolve the ambiguity in 'grounding conditions', which is in turn inherited from the syntactical ambiguity in 'grounding facts'. Here is an example of a frame 
principle: for all $\mathrm{z}$, the fact $z$ is a bill printed by the Bureau of Printing and Engraving grounds the fact $z$ is a dollar. The frame principle tells us that certain facts are grounding facts (in the first sense) for certain social facts; in doing so, it tells us what the grounding facts are (in the second sense).

Notice that a frame principle does not say simply that for all $\mathrm{z}$, if $\mathrm{z}$ is a bill printed by the Bureau of Printing and Engraving then $\mathrm{z}$ is a dollar; rather, it explicitly says something about grounding. Epstein writes: 'the antecedent is not just an accidentally sufficient condition [for the consequent]. It is the metaphysical reason that something is a dollar or a promise. [Frame principles] tell us what grounds what.' (76) I will return to this point below.

Anchoring. In virtue of what is a frame principle true? Typical answers will cite facts about our individual, joint and collective attitudes, intentions, actions, and conventions. For Epstein, the relation between such facts and a frame principle is the relation of anchoring, and (I think) the facts which do this anchoring work can be called 'anchors'. It seems clear that, for Epstein, it is the frame principle, or the fact that the grounders ground the groundees, which is itself anchored. Notice again that the anchoring facts do not just make it the case that if something is printed by the Bureau of Engraving and Printing it is a dollar bill; they make it the case that a grounding relation holds between the two relevant facts.

\section{Conjunctivism}

I am inclined to think that, given Epstein's desiderata and constraints, the groundinganchoring distinction is not best thought of as a distinction between two different relations, but as a distinction between two different ways in which facts or entities can be structured as grounds of social facts. The fact that Billy was produced by the Bureau of Printing and Engraving is a ground of the fact that Billy is a dollar. And the fact that we have collectively accepted the exclusive authority of the Bureau of Printing and Engraving is the ground of the relationship between those two more particular facts about Billy.

I think this means that I am defending the view Epstein dubs 'conjunctivism'.

...conjunctivism...is the view that the grounds for a social fact include the anchors, in addition to what [Epstein is] calling the grounds. Anchors, according to the conjunctivist, are just another kind of ground...The conjunctivist makes a strong claim about social facts: every social fact has two different kinds of grounds. (115) 
So, for example, the conjunctivist says that the fact that we have collectively accepted the exclusive authority of the Bureau of Printing and Engraving grounds the frame principle, which expresses the grounding relationship between being a bill produced by the Bureau of Printing and Engraving and being a dollar; then the frame principle, together with the fact that Billy was indeed produced by the Bureau of Printing and Engraving, grounds the fact that Billy is a dollar.

Epstein rejects conjunctivism: his main objection is that (for reasons I explain below), he does not think that the frame principle is a ground for Billy's being a dollar. But notice that we could accept that the frame principle is not a ground for Billy's being a dollar, and yet insist that the fact that we collectively accept the authority of the Bureau of Printing and Engraving is itself the ground of the frame principle. We can retain the idea that frame principles have grounds, rather than needing to invoke a special category of anchors to underpin frame principles. So it's not the relationship between collective acceptance and frame principle which supposedly requires us to distinguish between grounding and anchoring. Instead, it's the relationship between the frame principle and a particular social fact, such as the fact that Billy is a dollar.

\section{Counterfactuals and countertemporals}

So why doesn't Epstein think that the frame principle is a ground for Billy's being a dollar? As Epstein points out, we seem to treat frame principles and particular grounds symmetrically when thinking counterfactually. It seems true that if Billy had not been issued by the Bureau of Printing and Engraving, Billy would not have been a dollar: vary the grounds, and the social fact varies too. But likewise it seems true that if we had not collectively accepted that being issued by the Bureau of Printing and Engraving made something count as a dollar, then Billy would not have been a dollar. Vary the anchors and the social fact varies too.

Epstein accepts that conjunctivists can handle these counterfactuals with ease, and he sees this as a challenge to his own anti-conjunctivist stance. To handle the challenge, he suggests that we could adopt a specific theoretical framework, i.e. frames and a multiframe modal logic (p.78). Whilst I am no logical expert, I wonder Epstein really needs such heavy-duty machinery. Consider a seemingly-parallel case. If we are in general happy with groundingtalk, it is natural to distinguish the cause of an event from its grounds, for example by noting that a cause temporally precedes the event, whilst its grounds are simultaneous with it. A rabbit hops into the shrubbery: there are causal explanations at various levels for this (rabbit 
psychology, perception, evolution, presence of a predator, and so on). But in addition we might say that the rabbit hopped into the bush in virtue of all the undetached rabbit parts moving in a coherent manner into the shrubbery. This is an explanation in terms of grounds, rather than causes.

Thinking counterfactually we can note that if there had not been a predator present, the rabbit would not have hopped into the shrubbery. And we can note that if the undetached rabbit parts had not moved into the shrubbery, then the rabbit would not have hopped into the shrubbery. Treating both of these counterfactuals with what seems to be the same general approach does not amount to collapsing the distinction between causes and grounds. Thus it's not clear why Epstein could not treat counterfactuals which vary grounds and counterfactuals which vary anchors within the same general approach, without thereby collapsing the distinction between grounds and anchors.

Relatedly, I am puzzled by a disanalogy between Epstein's modal discussion and his temporal discussion. Just as we can consider social reality across possible worlds, we can likewise consider social reality across past (and future) times. Epstein claims that 'Certain social kinds, for instance, we explicitly anchor to apply across all situations, even retrospectively. Consider, for instance, the conditions for being a war criminal....We can sensibly ask whether Caligula was a war criminal, or whether Genghis Khan was... When we assess [social facts] across other times and possibilities, we do not deny that they obtain merely because the anchoring facts do not obtain at those times and possibilities.' (124)

The key point seems to be that we can discuss social reality at times when the grounds are different from the present (e.g. there are different material circumstances) whilst evaluating what we say about other times in light of our contemporary anchoring facts (what we now collectively accept). This suggests an important distinction between grounds and anchors, in opposition to conjunctivism. But Epstein overlooks the fact that there are contexts in which it is not sensible to ask whether Caligula was a war criminal, unless we mean to ask whether he violated whatever laws may have governed warfare at his time. Such imposition of modern categories onto historical figures is regarded by many (though not all) historians as anachronistic, and explanatorily fruitless. Thus socially-oriented historians of science, and sociologists of contemporary science, stress the importance of using 'actors' categories', i.e. concepts available to the scientists who are the subjects of study. (The ethnographic distinction between 'etic' and 'emic' fulfills a similar role.) 
This isn't just a historiographical issue. Looking ahead to the post-apocalyptic future, it makes perfect sense to say that Billy will no longer be a dollar bill once humanity has expired. This is exactly because the anchors for our currency systems will not exist at that time, even though the grounds will continue to exist, i.e. pieces of papers which were originally produced by the Bureau of Printing and Engraving. Indeed, Epstein's distinction between (what look to me like) two types of ground is very useful in helping us think through such cases.

I suggest that, in considering past or future times, we can hold our present anchors fixed and ask what grounds obtain at those other times (I take this to be Epstein's idea in asking whether Caligula was a war criminal). But equally, we can work with the anchors which are contemporaneous with the facts we are considering, as when we deny that Billy will be a dollar once humanity has died out, or deny that there were war criminals before the existence of the relevant legal framework. This is analogous to the way in which, as Epstein shows, when thinking counterfactually we are capable of varying the anchors and the grounds independently. None of this seems to tell against conjunctivism, or in favour of distinguishing the relation of anchoring from that of grounding.

\section{The Regress Argument}

Epstein presents a regress argument which is intended to show that anchors cannot be among the grounds, at least for any plausible account of anchoring. Suppose for reductio of conjunctivism that 'Billy is a dollar' is partially grounded by Billy's being a piece of paper issued by the Bureau of Printing and Engraving, and partially grounded by the fact that we collectively accept that if $\mathrm{x}$ is a piece of paper issued by the Bureau of Printing and Engraving, then that grounds the fact that $\mathrm{x}$ is a dollar. That's to say, suppose that the grounds are made up of the facts about Billy, and the fact that we collectively accept the relevant frame principle. As Epstein points out, on this picture we collectively accept something false. We collectively accept that if $\mathrm{x}$ is a piece of paper issued by the Bureau of Printing and Engraving, then that grounds the fact that $\mathrm{x}$ is a dollar. But by hypothesis, this is insufficient for grounding, because the fact of our collective acceptance is itself part of the ground.

It won't help to say instead that we collectively accept that if [we collectively accept that (if $\mathrm{z}$ is a piece of paper issued by the Bureau of Printing and Engraving, then that grounds the fact 
that $\mathrm{z}$ is a dollar) and Billy is a piece of paper] then Billy is a dollar: this is not psychologically plausible, and in any case would set us off down the rabbit hole of regress.

This argument turns on the idea that we collectively accept a proposition about grounding, rather than a weaker conditional. That is, we are pictured as collectively accepting that if $\mathrm{z}$ is produced by the Bureau of Printing and Engraving then this grounds the fact that $\mathrm{z}$ is a dollar, rather than simply that if $\mathrm{z}$ is produced by the Bureau of Printing and Engraving then $\mathrm{z}$ is a dollar. Without this, there would be no regress: the fact of our acceptance would make it true that if Billy was printed by the Bureau of Printing and Engraving then Billy is a dollar, and this together with the fact that Billy was indeed printed by the Bureau of Printing and Engraving ground the fact that Billy is a dollar.

\section{Constitutive Rules and Frame Principles}

Let's look again at why Epstein explicitly writes grounding into his frame principles. The notion of a frame principle is a generalisation of what Searle calls a 'constitutive rule'. According to Epstein, 'a constitutive rule is a principle that connects a set of grounding conditions to a particular social fact or a type of social fact. It articulates what the grounding conditions are for a social fact. This means that the constitutive rule is not among the grounding conditions for a social fact, but instead describes how the social is grounded.' (76) Searle uses the locution 'counts as' - 'Bills issued by the Bureau of Engraving and Printing (X) count as dollars (Y) in the United States (C)' (52). (For what it's worth, to my ear it is not clear whether or not 'counts as' expresses a grounding relation, e.g. the relation 'in virtue of this fact counts as'. One test is whether 'counts as' can be symmetric - a case where As count as Bs, and Bs count as As - but I haven't come up with a clean enough example of this.)

Constitutive rules, and by generalisation frame principles, are made true by facts about collective acceptance, joint commitment, or whatever plays this role in your preferred social metaphysical story. It doesn't follow that the content of what we accept, agree, commit to, or write into law needs to concern grounding. That is, the content of our collective acceptance might just be that bills produced by the Bureau of Printing and Engraving are dollars. Or, to take a worked example from chapter 7, we may collectively accept that if someone is a killer with deliberately premeditated malice aforethought, that person is a first degree murderer.

All this is compatible with Epstein's plausible claim that it is not mere happenstance that, for example, someone who is a killer with deliberately premediated malice aforethought is a 
murderer. For one thing, this conditional has a ground of its own, in our collective acceptance of its truth. And for another, this conditional together with the fact that (e.g.) Whitey Bulger is such a killer is enough to ground the fact that Whitey Bulger is a murderer. Overall, then, I don't think Epstein has given us good reason to think that we need to treat anchoring and grounding as different metaphysical relations. Indeed, Epstein himself notes that the work in the second part of the book (which I have not discussed in these comments) is independent of his rejection of conjunctivism. We can work with his very useful framework without accepting this additional commitment, and I look forward to doing so in future. This book should change the way we do social ontology, and change it for the better.

\section{References}

Guala, Francesco (2007): 'The Philosophy of Social Science: Metaphysical and Empirical' Philosophy Compass 2.6: 954-980.

Jenkins, Katharine (2016): Ontic Injustice, PhD dissertation submitted to the University of Sheffield.

Schaffer, Jonathan (2009): 'On What Grounds What', in Manley, D., Chalmers, D., and Wasserman, R. (eds.) Metametaphysics: New Essays on the Foundations of Ontology, Oxford University Press: 347-83.

Wilson, Jessica M. (2014): 'No Work for a Theory of Grounding', Inquiry 57 (5-6): 535-79. 